\title{
Replication of Tomato spotted wilt virus After Ingestion by Adult Thrips setosus is Restricted to Midgut Epithelial Cells
}

\author{
Jun Ohnishi, Leandra M. Knight, Daijirou Hosokawa, Ichiro Fujisawa, and Shinya Tsuda
}

First and third authors: Tokyo University of Agriculture and Technology, Faculty of Agriculture, 3-5-8 Saiwai, Fuchu, Tokyo 183-8509, Japan; and second, fourth, and fifth authors: National Agricultural Research Center, 3-1-1 Kan-nondai, Tsukuba, Ibaraki 305-8666, Japan. Accepted for publication 8 August 2001.

\begin{abstract}
Ohnishi, J., Knight, L. M., Hosokawa, D., Fujisawa, I., and Tsuda, S. 2001. Replication of Tomato spotted wilt virus after ingestion by adult Thrips setosus is restricted to midgut epithelial cells. Phytopathology 91:1149-1155.

If acquisition access feeding (AAF) is first given after adult eclosion, none of the nine thrips species able to serve as tospovirus vectors can become infective. The previous cellular investigations of this phenomenon, carried out only in Frankliniella occidentalis, suggested that infectivity was prevented because the type member of the tospoviruses, Tomato spotted wilt virus (TSWV), was unable to enter the midgut of adult thrips. The present study extends a cellular view of tospovirusthrips interactions to a species other than the western flower thrips, $F$. occidentalis. Our findings show that TSWV enters and replicates within the midgut of adult Thrips setosus, but does not infect cells beyond the

midgut epithelia. After AAF as adult, TSWV replicated in T. setosus midgut cells as indicated by significant increases in nucleocapsid $(\mathrm{N})$ protein detected by double-antibody sandwich enzyme-linked immunosorbent assay, and the presence of inclusions containing the S RNAencoded nonstructural and $\mathrm{N}$ proteins revealed by microscopic observations. Electron microscopic observations of adult insects showed that no infection occurred in cells beyond the midgut epithelia, and insects subsampled from the same cohorts could not transmit TSWV. In contrast, electron microscopy observations of larval T. setosus revealed that TSWV infected the midgut and muscle cells, and adult insects developing from these cohorts had infected salivary glands and were able to transmit TSWV. Mature virions were observed only in the salivary glands of adults developing from infected larvae. Our findings suggest that the barrier to infectivity in $T$. setosus adults differs from that shown for $F$. occidentalis adults.
\end{abstract}

Tomato spotted wilt virus (TSWV) is a single-stranded RNA member of the genus Tospovirus in the family Bunyaviridae (16). TSWV is one of the most important plant viruses (7), infecting numerous crops worldwide (21), and is transmitted by several species of thrips (Thysanoptera: Thripidae) in a propagative fashion $(5,26,30)$. The tripartite TSWV-RNA genome consists of small (S) and medium (M) ambisense segments and a large (L) negativestrand segment encoding six proteins from five open reading frames (16). The S RNA is a $2.9-\mathrm{kb}$ ambisense segment that encodes the nucleocapsid (N) and a nonstructural (NSs) protein (12). The NSs protein is present after translation in both the plant cell and insect vector $(26,30)$. Thus, NSs is often used as an indicator of viral replication.

Tospoviruses are currently transmitted by nine species of thrips (22), including Frankliniella occidentalis (Pergande), the western flower thrips, and Thrips setosus (Moulton), the light brown soybean thrips. As documented for $F$. occidentalis, when larval $T$. setosus acquire TSWV, the virus enters the midgut epithelial cells, replicates, moves to salivary glands during pupation, and is transmitted by adults (23). F. occidentalis has a broad host range, is the most common vector of TSWV, and is the thrips most often used for tospovirus transmission studies $(5,21)$. However, because $T$. setosus is endemic to Japan and transmits TSWV to susceptible crops such as tomato, eggplant, and legumes $(11,15)$, it was chosen as the study species for our experiments.

The maintenance of the complex interaction between TSWV, thrips, and plants requires the coordination, by continuous passage, of virus between plant and insect and the successful replication

Corresponding author: S. Tsuda; E-mail address: shinyat@affrc.go.jp

Publication no. P-2001-0926-01R

(c) 2001 The American Phytopathological Society and movement of virus within plant and insect tissues. Upon entering plant cells from the thrips vector, after replication, individual enveloped virions are released into, and accumulate in, the endoplasmic reticulum (ER) after double enveloped viruses from the Golgi fuse with the ER (10). Whereas most virions collect in the ER awaiting uptake by thrips, other virions move, cell-to-cell, through tubules in a nucleocapsid complex form (13). In thrips, however, the movement and assembly process of TSWV during insect developmental stages is still unclear. After thrips larvae ingest TSWV, it is absorbed through the apical membrane of midgut epithelial cells (26). Next, the virus replicates and moves across the basal lamina (BL), circulating in the hemocoel, and enters the salivary glands by an unknown mechanism. Finally, TSWV can successfully infect plants via thrips saliva produced in the lumen of the salivary glands of adult thrips (5). It has not been determined where and how TSWV crosses the midgut BL from the midgut lumen, fat body membrane, or salivary gland BL in thrips given acquisition access feeding (AAF) as larvae.

TSWV can be transmitted to plants by thrips given AAF in the larval stage; however, transmission cannot occur if acquisition feeding is after adult eclosion (5). Five possible barriers to adult transmission can be identified: (i) midgut infection, (ii) midgut escape, (iii) dissemination, (iv) salivary gland infection, and (v) salivary gland escape $(1,8)$. In this paper, we confirm that, as documented for $F$. occidentalis $(5,25)$, adult $T$. setosus can only transmit virus that is acquired in larval stages. However, contrary to adult acquisition in $F$. occidentalis, we detected an increase in $\mathrm{N}$ protein by double-antibody sandwich enzyme-linked immunosorbent assay (DAS-ELISA) over the first 3 days of infection after $\mathrm{AAF}$ as adult, indicating that replication was occurring. In addition, when viruliferous adult $T$. setosus were visualized by immunofluorescence microscopy (IFM) and immunogold transmission electron microscopy (TEM), N and NSs 
proteins were localized in, but remained confined to, midgut epithelial cells. Our results demonstrate that TSWV replication occurs in adult T. setosus midgut epithelial cells after adult AAF, and suggest the tospovirus interaction or mechanism of preventing escape from the midgut may be different among thrips vector species. Our results may also help to explain the variability in latent periods reported among individual thrips species. To our knowledge, this is the first investigation of adult acquisition in a thrips species other than the well-characterized $F$. occidentalis.

\section{MATERIALS AND METHODS}

Thrips maintenance and virus acquisition. Stock colonies of T. setosus (Moulton) were reared on caged pods of virus-free Vigna susquipedaris at 23 to $26^{\circ} \mathrm{C}$ under a 16-h light and 8-h dark cycle (18). Datura stramonium infected with TSWV collected from green pepper, Capsicum annuum, was used as the source for virus acquisition (23). Adult T. setosus, collected within 1 day after emerging from pupa in virus-free thrips colonies, were given $2 \mathrm{~h}$ AAF on infected $D$. stramonium leaves and were transferred to and maintained on virus-free $V$. susquipedaris. The adult thrips were collected at 0 (immediately after $2 \mathrm{~h} \mathrm{AAF),} \mathrm{1,} \mathrm{3,} \mathrm{5,} \mathrm{7,} \mathrm{and}$ 9 days after AAF from the virus-free $V$. susquipedaris and either processed for immunocytochemical analysis and TEM studies or tested for TSWV transmission. As a positive control for electron microscopy and immunofluorescence studies, first-instar larvae were given $2 \mathrm{~h}$ AAF on infected $D$. stramonium leaves and transferred, maintained, and processed in the same fashion as described for adult thrips. As negative controls, first-instar larvae were fed on virus-free $V$. susquipedaris leaves until adulthood, and adults from these virus-free thrips colonies were fed on virus-free $D$. stramonium for $2 \mathrm{~h}$ and transferred to and maintained on TSWVfree $V$. susquipedaris until being processed in the same manner as described previously.

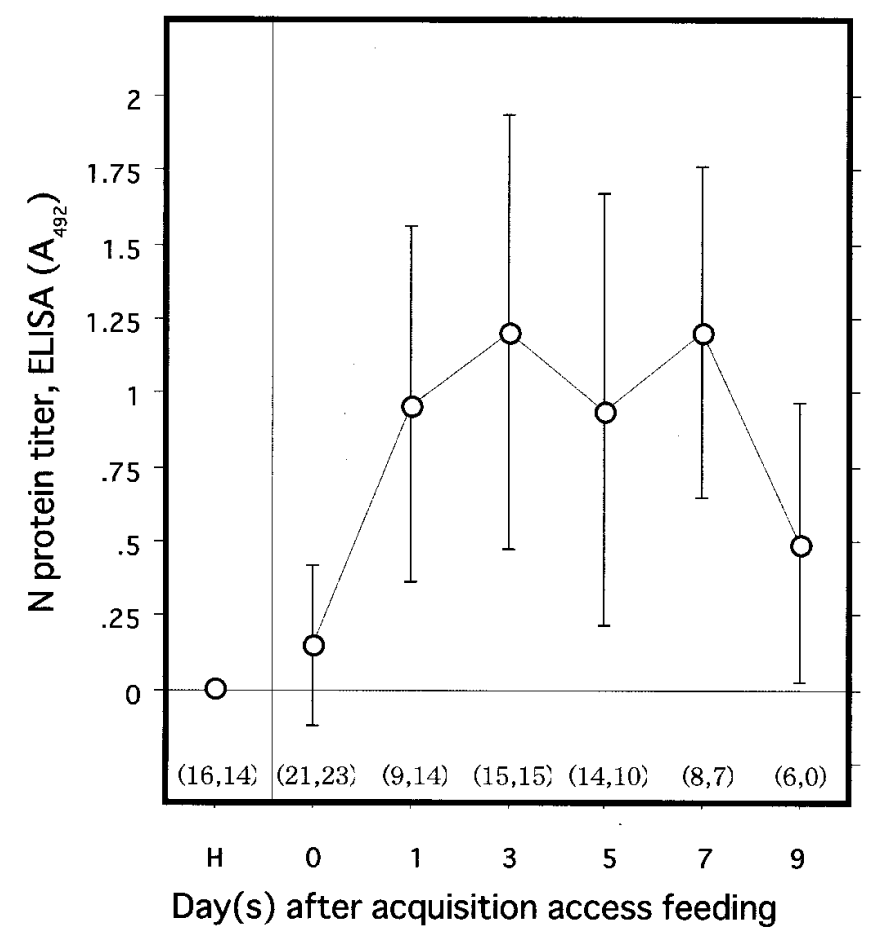

Fig. 1. Double-antibody sandwich enzyme-linked immunosorbent assay results at $0,1,3,5,7$, and 9 days after adult acquisition access feeding using monoclonal antibodies to the nucleocapsid $(\mathrm{N})$ protein. $\mathrm{H}$ indicates healthy adult thrips maintained on virus-free Datura stramonium. A (O) indicates the mean for each day, and error bars represent standard deviation. The numbers of thrips examined each day are in parenthesis (male, female).
Virus transmission assay and DAS-ELISA. Five male and five female adult thrips were randomly subsampled from each test group each day, and virus transmission was tested by exposing green pepper seedlings for 2 days, as previously described by Tsuda et al. (23). Levels of TSWV in adult thrips were measured at $0,1,3,5,7$, and 9 days after AAF by DAS-ELISA with monoclonal antibodies to the $\mathrm{N}$ protein (24). Adult thrips, sampled each day, were homogenized with a mortar and pestle in $50 \mu \mathrm{l}$ of $0.1 \mathrm{M}$ phosphate buffer ( $\mathrm{pH} 7.0$ ) containing $0.1 \%$ (vol/vol) 2-mercaptoethanol, $0.1 \%$ (wt/vol) bovine serum albumin (BSA), $10 \mathrm{mM}$ EDTA, and $0.15 \%$ (wt/vol) polyvinylpyrrolidone-40 (23). The absorbance of each sample was measured at $492 \mathrm{~nm}$ with an ELISA reader (MR600; Dynatech Laboratories Inc., Alexandria, VA) after $1 \mathrm{~h}$ incubation at $25^{\circ} \mathrm{C}$. Samples were considered positive if the optical density at $492 \mathrm{~nm}\left(\mathrm{OD}_{492}\right)$ was above 0.020 , which represented the average readings of 30 noninfected thrips plus triple the standard deviation. All readings were included in the mean for 0 days after AAF because amounts of virus uptaken and replicated by individual insects may not be enough to be detected by DASELISA. Crude purified $\mathrm{N}$ of TSWV was used for the positive control in DAS-ELISA.

Immunocytochemistry. In order to visualize the localization of the $\mathrm{N}$ and NSs proteins in infected thrips, a previously described IFM procedure (23) was modified as follows. Legs, antennas, and wings were removed from the body in fixative (ethanol/acetic acid/chloroform $=6: 3: 1, \mathrm{vol} / \mathrm{vol}$ ), and the body was embedded in Paraplast Plus (Oxford Labware, St. Louis). Serial longitudinal sections, 6 to $8 \mu \mathrm{m}$ thick, were mounted on poly-L-lysine precoated microscope slides and treated with $10 \%$ (wt/vol) fetal calf serum in phosphate-buffered saline (PBS), pH 7.0 (blocking buffer), for $30 \mathrm{~min}$ and blotted dry. Next, sections were incubated for $1 \mathrm{~h}$ in anti-N protein antiserum house-in-made (23) or anti-NSs protein antiserum (12) provided by D. Peters (Wageningen Agricultural University). Preimmune rabbit serum, obtained before producing anti-N protein antiserum, served as a negative control. The sections were washed four times with $0.05 \%$ (vol/vol) Tween 20 in PBS (washing buffer), incubated with fluorescein isothiocyanate-conjugated goat anti-rabbit immunoglobulin $\mathrm{G}(\mathrm{IgG})$ antibody (1CN Pharmaceuticals Inc., Costa Mesa, CA) for $1 \mathrm{~h}$, dipped for $15 \mathrm{~min}$ in washing buffer four times (in the dark), and finally examined with a fluorescence microscope (AH3-RFC; Olympus, Japan).

Immunogold labeling and TEM. Legs, antennas, and wings were removed from the body in 1 drop of $50 \mathrm{mM}$ sodium cacodylate, $\mathrm{pH} 7.4$, containing $4 \%$ (wt/vol) paraformaldehyde, $1 \%$ (vol/vol) glutaraldehyde, and $1.5 \mathrm{mM}$ calcium chloride (fixative) before the body was immersed in it at $4^{\circ} \mathrm{C}$ for $1 \mathrm{~h}$. The head and abdomen were separated from the thorax, and the three segments were soaked in fixative at $4^{\circ} \mathrm{C}$ for at least $12 \mathrm{~h}$. The segments were then dehydrated in a series of 50 to $100 \%$ ethanol solutions and finally embedded in LR White (London White Resin, UK). After allowing the specimens to polymerize at $50^{\circ} \mathrm{C}$ for 48 to $72 \mathrm{~h}, 60-$ to $90-\mathrm{nm}$ sections were fixed to formva-coated nickel grids, which were placed on a drop of $1 \%(\mathrm{wt} / \mathrm{vol}) \mathrm{BSA}$ in PBS (blocking buffer) for $30 \mathrm{~min}$, incubated for $1 \mathrm{~h}$ at $37^{\circ} \mathrm{C}$ with anti$\mathrm{N}$ or anti-NSs protein antiserum, described in immunocytochemistry, washed four times with PBS, and incubated for $30 \mathrm{~min}$ at $37^{\circ} \mathrm{C}$ with $15 \mathrm{~nm}$ of colloidal gold-conjugated goat anti-rabbit IgG antibody (Amersham Pharmacia Biotech, Buckinghamshire, UK) diluted in blocking buffer. Finally, sections were washed with PBS four times and distilled water once, stained with lead citrate and uranyl acetate, and examined by TEM (1210; JEOL, Tokyo) at $80 \mathrm{kV}$ electron acceleration. Both antisera used in the IFM and immunogold TEM experiments reacted with virus-specific structures in TSWV-infected D. stramonium cells; viroplasms (VP) for anti-N antibodies and fibrous paracrystalline arrays (FPA) for antiNSs antibodies in TEM observation (27). The preimmune rabbit serum did not react with equivalent sections of structures in viruli- 
ferous thrips, larvae, and adults in either IFM (except for autofluorescence from thrips bodies) or immunogold TEM experiments (data not shown).

\section{RESULTS}

Adult T. setosus are unable to transmit TSWV when given adult AAF. Similar to previous results with $F$. occidentalis $(17,25)$, the transmission efficiency for individual $T$. setosus after adult AAF was $0 \%$ for the 60 thrips tested through day 9. In comparison, an equivalent $2 \mathrm{~h}$ AAF for first-instar T. setosus larvae resulted in $65 \%(n=26)$ transmission for individual adults 13 days after AAF (data not shown). This is consistent with a previous study in which $33.3 \%$ of $F$. occidentalis adults transmitted TSWV after a $24 \mathrm{~h}$ larval AAF periods (17).

TSWV multiplication in $T$. setosus adults. DAS-ELISA results showed an increase in $\mathrm{N}$ protein in adult thrips after a short 2 h AAF given directly after adult eclosion (Fig. 1). Previously, $2 \mathrm{~h}$ AAF was sufficient to allow detection of replication of the virus in thrips $(23,30)$. Values in parentheses presented in Figure 1 are for both genders because no significant difference $(F=1.69$; $P>0.2$ ) was seen between females and males in this study. Immediately after $2 \mathrm{~h}$ AAF, thrips had an average $\mathrm{OD}_{492}$ of $0.150 \pm$ 0.271 (mean $\pm \mathrm{SD}, n=44$ ). The $\mathrm{OD}_{492}$ sharply increased to $0.96 \pm$ 0.601 (mean $\pm \mathrm{SD}, n=23$ ) 1 day after AAF. Virus titer continued to rise, peaking at $1.20 \pm 0.735$ (mean $\pm \mathrm{SD}, n=30) 3$ days after AAF. This $\mathrm{OD}_{492}$ is similar to the maximum mean of virus detected in larval thrips infections (23), suggesting that sufficient virus was in epithelial cells to allow virus transmission if the barrier in adult insects was permeable. Interestingly, the virus titer in adult thrips decreased slightly on day 5 to $0.941 \pm 0.726$ (mean \pm SD, $n=24)$ and increased to $1.20 \pm 0.556$ (mean $\pm \mathrm{SD}, n=15)$ on day 7 . At 9 days after AAF, the virus titer decreased to $0.50 \pm 0.471$ (mean $\pm \mathrm{SD}, n=6$ ). The ELISA data from adults collected on day 7 does not correspond to the immunocytochemical data presented below. Additional studies are needed to resolve these differences. However, the pattern of adult infection mirrors that observed in larval infection (23).

TSWV restriction to midgut epithelial cells. Because ELISA results do not demonstrate the location of virus replication, we studied this by detecting TSWV N and NSs proteins in adult thrips by IFM and immunogold TEM. Immunofluorescence labeling of the $\mathrm{N}$ and NSs proteins revealed TSWV infection, over time, in thrips given AAF as larva (Fig. $2 \mathrm{~B}$ and $\mathrm{C}$ ) or as adult (Fig. 2D to I). Figure 2A shows background autofluorescence in a nonviruliferous adult treated with anti-N protein antiserum. A positive bright green signal was observed from anterior midgut cells in which the N (Fig. 2D) and NSs (Fig. 2G) proteins was detected in an adult thrips 1 day after AAF. The bright positive signal appearing extensively throughout midgut epithelial cells
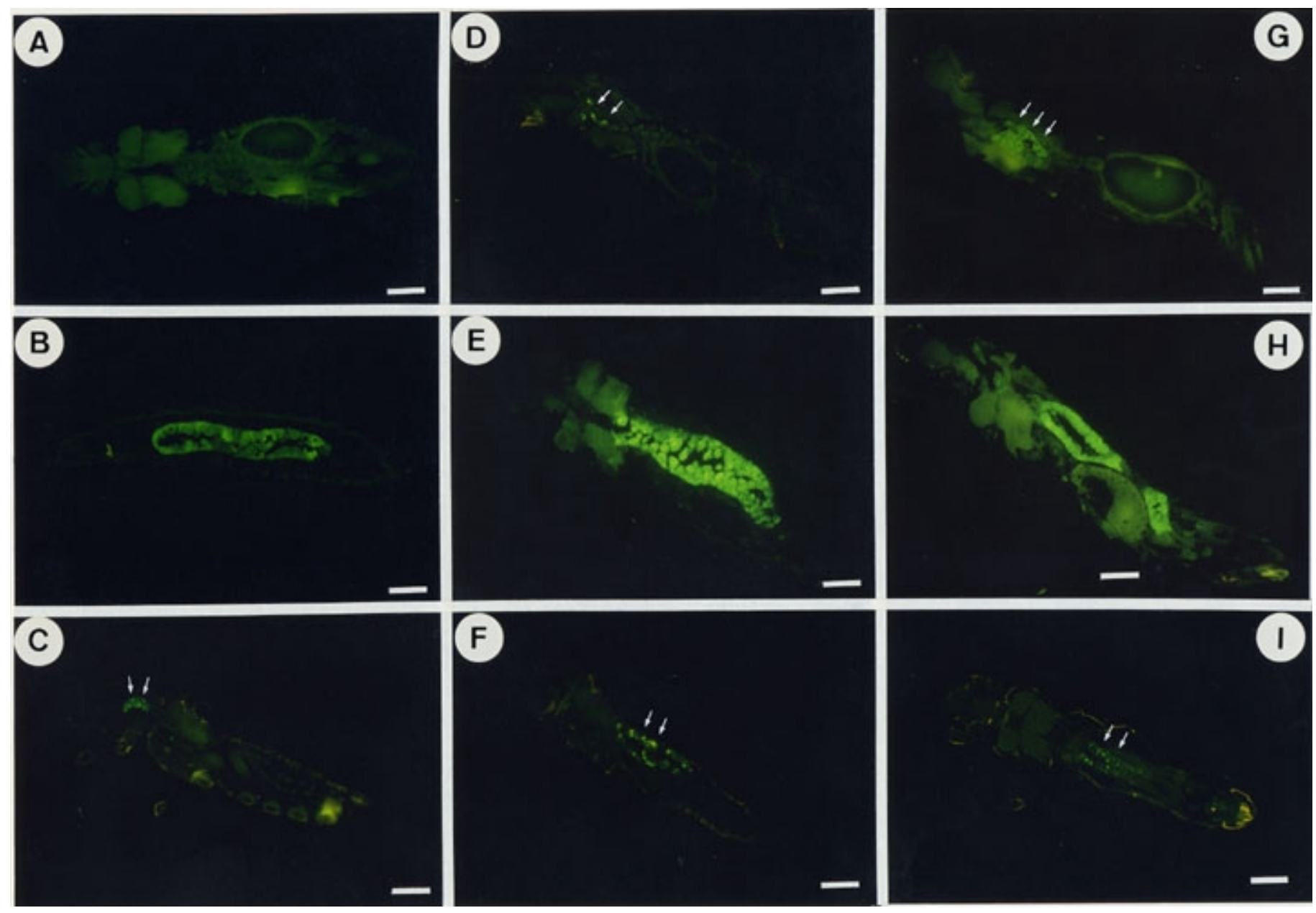

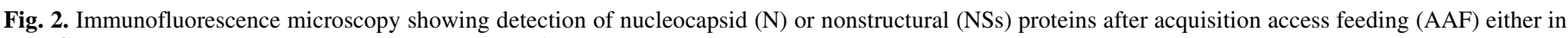

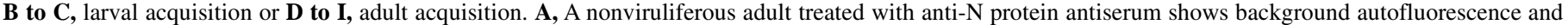

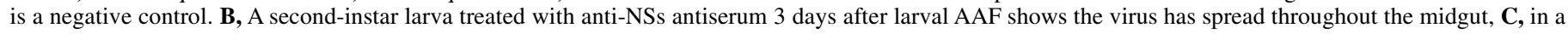

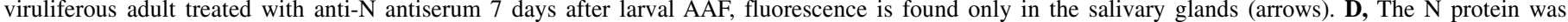

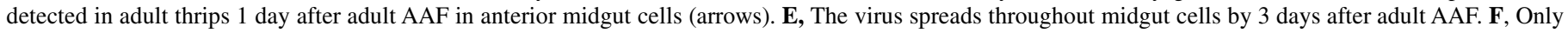

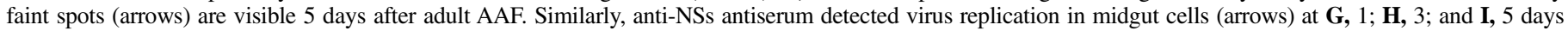
after adult AAF. A to I, The scale bars are $100 \mu \mathrm{m}$. 
was not observed from muscle cells, hemocoel, salivary glands, and salivary gland ducts of larvae (Fig. 2B, treated with anti-NSs) or adults (Fig. 2E and $\mathrm{H}$, for the $\mathrm{N}$ and NSs protein, respectively) 3 days after AAF. Thus, signal was clearly confined by the midgut epithelial cells or its BL. The signal from both $\mathrm{N}$ (Fig. 2F) and NSs (Fig. 2I) proteins decreased 5 days after adult AAF, until only faint spots were detected in the midgut and no signal was detected in the muscle cells, hemocoel, salivary glands, and salivary gland ducts. In contrast, after eclosion of adults given larval AAF (Fig. $2 \mathrm{C}$ ), fluorescence associated with anti-N protein antisera was detected in the salivary glands 7 days after AAF. No fluorescence associated with either anti-N or anti-NSs protein antiserum was detectable at 9 and 11 days after AAF (data not shown). The same infection pattern was observed for 12 individual thrips viewed by this method. Immunofluorescence observations showed that virus accumulation was restricted by the midgut epithelia or the BL at the peak of infection on day 3 .

Immunogold-labeled electron micrographs show individual TSWV structures bound to N or NSs antibody-gold particle complexes in adult thrips provided adult AAF (Fig. 3A to D) or larval AAF (Fig. 3E to $\mathrm{H}$ ). The $\mathrm{N}$ protein was associated with VP (Fig. 3A, C, D, E, G, and H) and the NSs protein with FPA (Fig. 3B and F) within the microvilli and cytoplasm of midgut epithelial cells of thrips that acquired the virus as either adults (Fig. 3A and B) or larvae (Fig. 3E and F) 3 days after AAF. Most significantly, postadult acquisition $\mathrm{N}$ protein was found concentrated in VP at the perimeter of the midgut. Although $\mathrm{N}$ protein was detected as close as $100 \mathrm{~nm}$ from the $\mathrm{BL}$, it was not detected in muscle cells or hemocoel (Fig. 3C), whereas in thrips that acquired virus as larvae, $\mathrm{N}$ protein was detected in muscle cells on the hemocoel side of the BL (Fig. 3G). The high virus titer detected by ELISA and immunofluorescence suggests there was sufficient virus to diffuse across the midgut if the virus could exit midgut cells. The lack of $\mathrm{N}$ protein in salivary glands of adult thrips given adult AAF after 7 days (Fig. 3D) suggests that the virus does not exit from gut cells in these adults in contrast to adults having larval acquisition in which virus particles were observed budding into the salivary gland duct (Fig. 3H). Similar to immunofluorescence data, TEM showed that the N and NSs proteins can be detected in the midgut epithelial cells of thrips until at least 5 days after adult $\mathrm{AAF}$, but that they could not be detected in the midgut BL, hemocoel, or muscle cells. The same structural patterns were observed in seven individual thrips viewed by this method.

\section{DISCUSSION}

In the case of adult $T$. setosus having adult AAF, our results show that virus replication occurs and is confined within the midgut BL. This is clearly distinct from the lack in virus accumulation in F. occidentalis, which is best explained by rapid virus degradation before replication (25). It is likely that this difference between the two species is attributable to differences in digestion rates, insect immune responses, or viral interference specific to vector species.

As well as finding numerous similarities between TSWV transmission by $T$. setosus and $F$. occidentalis, some important differences were found. Most significantly, our findings contradict the concept that TSWV can only replicate in thrips vectors if given larval AAF $(17,25)$. Comparing our data with those reported for $F$. occidentalis, significant differences were shown by ELISA between the abundance of $\mathrm{N}$ protein and length of virus replication occurring within these two thrips species. In F. occidentalis, the $\mathrm{N}$ protein detected steadily decreased over the first $24 \mathrm{~h}$ after adult AAF (25); however, in T. setosus it sharply increased over the first 3 days after AAF, and remained detectable through 9 days. Whereas the highest titers of virus accumulation detected by ELISA in adult $F$. occidentalis after adult AAF were not so high (ranging from 0.025 to 0.358 with mean $\mathrm{OD}_{405}$ readings $=$
$0.109 \pm 0.165$ ) in the first $24 \mathrm{~h}$ after AAF, most adult $T$. setosus showed $1.20 \pm 0.735$ of $\mathrm{OD}_{492} 3$ days after adult AAF. This is considerably different between $F$. occidentalis and $T$. setosus, but direct comparisons cannot be made because of differences in detection approaches and antibodies used. In fact, existence of a midgut escape barrier in $F$. occidentalis has been demonstrated, which prevents virus invasion to the midgut from the lumen, thereby not allowing virus accumulation in midgut epithelial cells (25). Similar results for $F$. occidentalis after adult acquisition have also been reported. In adults given adult AAF, Nagata et al. (17) found no TSWV infection of any cells 3 days after AAF $(n=8)$, with faint detection in epithelial cells in 1 out of 18 adult thrips at 6 days and in 1 out of 36 at 9 days. In contrast, we found $100 \%$ of adult $T$. setosus were infected at 3 days $(n=30)$. Furthermore, $T$. setosus can acquire TSWV as adult, and viral accumulation and replication occurs up to at least 3 days after AAF as shown by the presence of virus-specific cytoplasmic structures, VP and FPA, which were also observed in F. occidentalis that acquired TSWV as larvae.

Although it has not been confirmed in F. occidentalis given adult AAF, Ullman et al. (25) hypothesized that the proteins deteced by ELISA are actually ingested virions of plant origin and that the low abundance of TSWV detected does not indicate de novo replication. In $T$. setosus given adult AAF, degradation of TSWV appears slower or does not occur, allowing for virus replication. Whether the ability of the virus to replicate in T. setosus but not in $F$. occidentalis is attributable to an innately weaker or inefficient defense response of $T$. setosus or to a virus adaptation or suppression mechanism specific to $T$. setosus defenses remains unclear. Results from further experiments comparing vector response with tospovirus infection are sure to yield intriguing and useful information, perhaps uncovering RNAi or other insect vector encoded resistance to viral attack, or differences in the ability of the virus to silence the defense mechanism of different vector species $(4,28)$. Thus, even this seemingly insignificant difference in virus accumulation within the two species could lead to insights in curbing the spread of TSWV.

Even though infection does not progress to the hemocoel in either F. occidentalis or $T$. setosus after adult AAF, we believe that the mechanism behind this may be distinct in each species. Variability among individual thrips and between different isolates of TSWV may underlie the widely varying latent periods reported (5). Although our data is insufficient to shed light on the correct answer, several reasons may explain the inability of TSWV to cross the T. setosus midgut BL. First, proteins necessary for attachment to or movement across the BL may be unable to fold or aggregate correctly due to the midgut environment. Second, a developmental stage-dependent midgut escape barrier may exist.

The lack of virus movement across the adult $T$. setosus midgut BL into the hemocoel after adult AAF has several possible explanations. Without the presence of necessary thrips membrane receptors, possible host cofactors, and virus ligand at all membrane barriers, ingested virions cannot cross membrane barriers to reach the salivary glands $(1,5,8)$. Our experiments could not confirm the presence and function of proteins possibly involved in midgut escape, such as G1, G2, or NSm, which must be functional over the viral life cycle in nature. Therefore, we cannot rule out the possibility that virus containment within the midgut BL may be due to defective formation of appropriate movement complexes. The nature of the barrier in T. setosus is not yet fully understood, but could involve defective replication and maturation, i.e., poor formation of appropriate complexes for movement. Alternatively, the midgut $\mathrm{BL}$ may lack proper physical structures or receptor proteins needed for virus movement and infection beyond the midgut.

The midgut of many insects undergoes morphological and physiological changes through the course of their development (2), and the difference in restriction between adults and larvae 

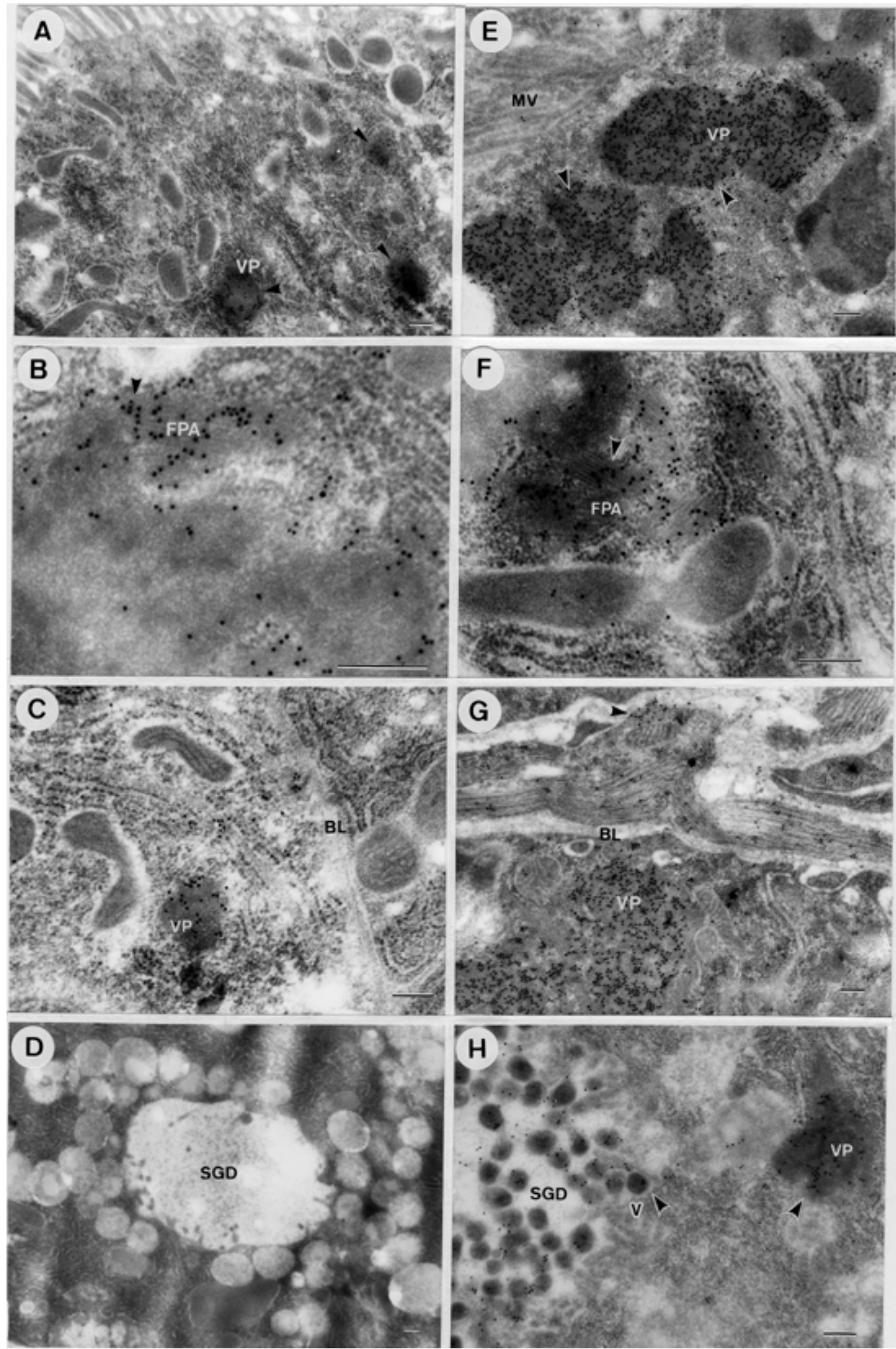

Fig. 3. Electron micrographs of infected midgut epithelial cells and salivary glands after acquisition access feeding (AAF) as $\mathbf{A}$ to $\mathbf{D}$, adult or $\mathbf{E}$ to $\mathbf{H}$, larva. Ultrathin sections were immunolabeled with either nucleocapsid $(\mathrm{N})$ or nonstructural (NSs) protein antiserum, and labeled with 15-nm colloidal goldconjugated goat anti-rabbit immunoglobulin $\mathrm{G}$ antibody. A, The N protein accumulated in viroplasms (VP; arrowheads) in midgut epithelia 3 days after adult AAF. B, The NSs protein was detected in fibrous paracrystalline arrays (FPA) 3 days after adult AAF. C, N protein accumulated in VP concentrated in the cytoplasm of the basal lamina (BL) of the midgut, but not in midgut BL or hemocoel 5 days after adult AAF. D, Lack of detection of N protein in salivary gland cells 7 days after AAF, with no virus particles observed in the duct of salivary glands. E, The N protein accumulating in VP (arrowheads) in the midgut epithelia of the infected larva 3 days after AAF as larva. F, The NSs protein accumulating in a FPA (arrowhead) in midgut epithelial cells of the infected larva in the same stage as E. G, N protein in VP (arrowhead) in muscle cells on the hemocoel of the BL and in the midgut cell 5 days after larval AAF. H, The salivary gland cells of an adult thrips that acquired virus in larval stages showing VP (right arrowhead) in the cytoplasm, and Tomato spotted wilt virus (TSWV) virions (left arrowhead) in the duct 7 days after larval AAF, immunolabeled with the anti-N protein antibody. MV = microvilli; SGD = salivary gland duct; and V = TSWV virion. A to $\mathbf{H}$, The scale bars represent $200 \mathrm{~nm}$. 
may be due to differential expression of barriers during thrips development (17). Little is known, however, about thrips morphology or physiology at each developmental stage. More in depth study of midgut tissues is required to clarify the barrier in adult thrips. Although barriers in several arthropod vectors of plant viruses have been established $(1,8)$, these barriers remain poorly understood. The following examples support the hypothesis that the $\mathrm{BL}$ of the thrips midgut serves as a barrier to virus transmission $(1,6,8)$. A specialized BL that controls virus uptake contains a putative receptor to which viruses attach to on the hemocoel side before penetration into the salivary glands as previously described by Peiffer et al. (20). Data by Peiffer et al. (20) shows that, in aphids, the BL influences luteovirus transmission by regulating virion penetration into the salivary glands from the hemocoel. A barrier at the BL, which restricts the virus crossing from midgut cells to the hemocoel, similar to that found for T. setosus in the present study, was also described (19). Dissemination of $L a$ Crosse virus (LACV) in the Aedes triseriatus mosquito is controlled by a midgut barrier at the BL, which can be bypassed by injecting the virus into the hemocoel of the vector, resulting in a significant increase in transmission rate (19). Similar experiments with TSWV in thrips that would allow the virus to bypass the midgut BL have not yet been reported. Our data, however, clearly indicates that TSWV transmission requires that the virus have the capacity to cross the midgut BL.

It has been suggested that TSWV penetrates thrips midgut epithelial cells by receptor-mediated endocytosis, because TSWV envelope, consisting of glycoproteins and membrane, is necessary for attachment to and interaction with a putative receptor from the abdomen of $F$. occidentalis (3), similar to other insect vectors (9). The putative receptor, a 50-kDa protein, may regulate the uptake of TSWV into thrips midgut epithelial cells because quantitative existence of the protein in the abdomen is more abundant in $F$. occidentalis larvae than in adults (3). This is consistent with data showing that adult $F$. occidentalis was unable to acquire TSWV when given AAF as adult (25). In the case of $T$. setosus, the amount of $50-\mathrm{kDa}$ protein in the abdomen of adult $T$. setosus may be as abundant as that in larvae.

When $F$. occidentalis is given larval AAF, virions have been observed by TEM in the midgut lumen and across the apical membrane, but were confined within the cytoplasm of midgut epithelial cells. Particles were not observed near the lumen or cytoplasm of hindgut epithelial cells, hemolymph, fat body, nerve, or salivary glands, although numerous VP and FPA were easily found in cells throughout the thrips body $(5,26)$. Significantly, intact virus particles were not observed in the viruliferous $T$. setosus after larval AAF in midgut epithelia, hemocoel, and muscle cells in developmental stages in TEM observations, except in the lumen of adult salivary glands after eclosion. Thus, we believe that our data supports the hypothesis that transtadial intracellular movement occurs in the form of RNA-N complexes that do not mature into enveloped viruses until they reach the salivary glands (5). In contrast, Nagata et al. (17) suggested that virus intracellular movement between the midgut and salivary glands involves an intact enveloped virion.

There are differences in the biology of the thrips genera, Thrips and Frankliniella, which could explain some of our results. One example of the individuality of $T$. tabaci, $F$. occidentalis, $F$. schultzei, and $F$. intonsa is the difference in transmission efficiency (29). More importantly, T. setosus consumes only leaves, whereas $F$. occidentalis feeds mainly on pollen (14), and the food source may influence the physiology, structure, and $\mathrm{pH}$ of the midgut, in turn affecting virus maturation or movement (5). For example, in the LACV transmitted by mosquitoes, the proper $\mathrm{pH}$ and enzymatic processing of viral membrane proteins are required for virus stability, fusion, and dissemination (5).

Our data shows that, similar to luteovirus-aphid interactions, vector-specific interactions vary at the cellular level for tospoviruses and their thrips vectors. Depending on the specific luteovirus $\times$ aphid species combination, the BL of the accessory salivary gland may act as an absolute barrier to transmission by preventing virus attachment, or impeding penetration, thus reducing transmission efficiency (20). This suggests that transmission efficiency of an aphid species or biotype may be partially regulated by the affinity or charge (anionic or cationic) of the virus for molecules located on the surface of the accessory salivary gland BL. The two different thrips species examined in the present study showed respective acquisition efficiency when given adult acquisition, suggesting from previous luteovirus/aphid reports that the midgut BL of thrips contains specific components involved in the transmission efficiency of tospoviruses. Whether the membrane escape barrier blocking virus transmission in adult $T$. setosus is truly present in adult $F$. occidentalis must be clarified by virus injection studies. Additional work is thus required to identify the composition of the $\mathrm{BL}$ from two different thrips and components that may specifically interact with tospovirus directly. The phenomena observed in our study clearly demonstrated that adult $T$. setosus do not possess the same midgut escape barrier shown in $F$. occidentalis, but nonetheless lose virus transmissibility in the same way as $F$. occidentalis after adult AAF.

\section{ACKNOWLEDGMENTS}

We dedicate this manuscript to D. Hosokawa (1937-1999) who did not live to see its publication. We thank D. E. Ullman and J. W. Moyer for their helpful comments and suggestions and D. Peters for providing the anti-NSs protein antiserum.

\section{LITERATURE CITED}

1. Ammar, E. D. 1994. Propagative transmission of plant and animal viruses by insects: Factors affecting vector specificity and competence. Adv. Dis. Vector. Res. 10:289-331.

2. Baldwin, K. M., Hakim, R. S., Loeb, M. J., and Sadrud-Din, S. Y. 1996. Midgut development. Pages 31-54 in: Biology of the Insect Midgut. M. J. Lehane and P. F. Billingsley, eds. Chapman \& Hall, London, UK.

3. Bandla, M. D., Campbell, L. R., Ullman, D. E., and Sherwood, J. L. 1998. Interaction of tomato spotted wilt tospovirus (TSWV) glycoproteins with a thrips midgut protein, a potential cellular receptor for TSWV. Phytopathology 88:98-104.

4. Fire, A., Xu, S., Montgomery, M. K., Kostas, S. A., Driver, S. E., and Mello, C. C. 1998. Potent and specific genetic interference by doublestranded RNA in Caenorhabditis elegans. Nature 391:806-811.

5. German, T. L., Ullman, D. E., and Moyer, J. W. 1992. Tospoviruses: Diagnosis, molecular biology, phylogeny, and vector relationships. Annu. Rev. Phytopathol. 30:315-348.

6. Gildow, F. E., and Gray, S. M. 1993. The aphid salivary gland basal lamina as a selective barrier associated with vector-specific transmission of barley yellow dwarf luteoviruses. Phytopathology 83:1293-1302.

7. Goldbach, R., and Peters, D. 1994. Possible causes of the emergence of tospovirus diseases. Semin. Virol. 5:113-120.

8. Hardy, J. L. 1988. Susceptibility and resistance of vector mosquitoes. Pages 87-126 in: The Arboviruses: Epidemiology and Ecology. T. P. Monath, ed. CRC Press, Boca Raton, FL.

9. Kaslow, D. C., and Welburn, S. 1996. Insect-transmitted pathogens in the insect midgut. Pages 432-462 in: Biology of the Insect Midgut. M. J. Lehane and P. F. Billingsley, eds. Chapman \& Hall, London, UK.

10. Kikkert, M., van Lent, J., Storms, M., Bodegom, P., Kormelink, R., and Goldbach, R. 1999. Tomato spotted wilt virus particle morphogenesis in plant cells. J. Virol. 73:2288-2297.

11. Kobatake, H., Osaki, T., and Inouye, T. 1984. The vector and reservoirs of tomato spotted wilt virus in Nara Prefecture. Ann. Phytopathol. Soc. Jpn. 50:541-544.

12. Kormelink, R., Kitajima, E. W., de Hann, P., Zuidema, D., Peters, D., and Goldbach, R. 1991. The nonstructural protein (NSs) encoded by the ambisense S RNA segment of tomato spotted wilt virus is associated with fibrous structures in infected plant cells. Virology 181:459-468.

13. Kormelink, R., Storms, M., van Lent, J., Peters, D., and Goldbach, R. 1994. Expression and subcellular location of the NSm protein of tomato spotted wilt virus (TSWV), a putative viral movement protein. Virology 200:56-65.

14. Mound, L. A., Heming, B. S., and Palmer, J. M. 1980. Phylogenetic re- 
lationships between the families of recent Thysanoptera (Insecta). Zool. J. Linn. Soc. Lond. 69:111-141.

15. Murai, T. 2001. Life history study of Thrips setosus. Entomol. Exp. Appl. 100:245-251.

16. Murphy, F. A., Fauquet, C. M., Bishop, D. H. L., Ghabrial, S. A., Jarvis, A. W., Martelli, G. P., Mayo, M. A., and Summers, M. D. 1995. Tospovirus. Pages 313-314 in: Virus Taxonomy, Archives of Virology. Suppl. 10. Springer-Verlag, New York.

17. Nagata, T., Inoue-Nagata, A. K., Smid, H. M., Goldbach, R., and Peters, D. 1999. Tissue tropism related to vector competence of Frankliniella occidentalis for tomato spotted wilt tospovirus. J. Gen. Virol. 80:507515.

18. Ohnishi, J., Hosokawa, D., Murai, T., and Tsuda, S. 1999. A simple rearing system for Thrips setosus Moulton (Thysanoptera: Thripidae) using a leaf cage method for the transmission experiment of tomato spotted wilt tospovirus. Appl. Entomol. Zool. 34:497-500.

19. Paulson, S. L., Grimstad, P. R., and Craig, G. B. J. 1989. Midgut and salivary gland barriers to La Crosse virus dissemination in mosquitoes of the Aedes Triseriatus Group. Med. Vet. Entomol. 3:113-124.

20. Peiffer, M. L., Gildow, F. E., and Gray, S. M. 1997. Two distinct mechanisms regulate luteovirus transmission efficiency and specificity at the aphid salivary gland. J. Gen. Virol. 78:495-503.

21. Peters, D. 1998. An updated list of plant species susceptible to tospoviruses. Pages 107-110 in: Fourth International Symposium on Tospovirus and Thrips in Floral and Vegetable Crops. D. Peters and R. Goldbach, eds. Wageningen, the Netherlands.

22. Tsuda, S. 1999. Tomato spotted wilt tospovirus: Plant-infecting Bunya- viridae. Virus 49:119-130

23. Tsuda, S., Fujisawa, I., Ohnishi, J., Hosokawa, D., and Tomaru, K. 1996. Localization of tomato spotted wilt tospovirus in larvae and pupae of the insect vector Thrips setosus. Phytopathology 86:1199-1203.

24. Tsuda, S., Hanada, K., Fujisawa, I., Kameya-Iwaki, M., and Tomaru, K. 1994. The demonstration of strain-specific antigenic determinants on nucleocapsid of tomato spotted wilt virus by monoclonal antibodies. Ann. Phytopathol. Soc. Jpn. 60:216-220.

25. Ullman, D. E., Cho, J. J., Mau, R. F. L., Westcot, D. M., and Custer, D. M. 1992. A midgut barrier to tomato spotted wilt virus acquisition by adult western flower thrips. Phytopathology 82:1333-1342.

26. Ullman, D. E., German, T. L., Sherwood, J. L., Westcot, D. M., and Cantone, F. A. 1993. Tospovirus replication in insect vector cells: Immunocytochemical evidence that the nonstructural protein encoded by the S RNA of tomato spotted wilt tospovirus is present in thrips vector cells. Phytopathology 83:456-463.

27. Urban, L. A., Huang, P.-Y., and Moyer, J. W. 1991. Cytoplasmic inclusions in cells infected with isolates of $\mathrm{L}$ and I serogroups of tomato spotted wilt virus. Phytopathology 81:525-529.

28. Washburn, J. O., Kirkpatrick, B. A., and Volkman, L. E. 1996. Insect protection against virus. Nature 383:767.

29. Wijkamp, I., Almarza, N., Goldbach, R., and Peters, D. 1995. Distinct levels of specificity in thrips transmission of tospoviruses. Phytopathology 85:1069-1074.

30. Wijkamp, I., Van Lent, J., Kormelink, R., Goldbach, R., and Peters, D. 1993. Multiplication of tomato spotted wilt virus in its insect vector Frankliniella occidentalis. J. Gen. Virol. 74:341-349. 